\title{
PARA ALÉM DA CHINA: CAPACIDADE OCIOSA E INVESTIMENTO ESTRANGEIRO DIRETO NAS FORMAÇÕES SOCIOESPACIAIS AFRICANAS NO INÍCIO DO SÉCULO XXI
}

Resumo: O crescimento recente da maior parte das economias africanas levou a produção de numerosas análises que condicionaram o fenômeno em questão ao dinamismo econômico chinês. Contudo, para além da influência evidente do país asiático - que opera na África por meio de acordos bilaterais, empréstimos e diferentes tipos de investimentos - deve-se também levantar quais são as condições especificas das forças produtivas das 54 formações socioespaciais africanas na atualidade. O entendimento dessas especificidades - bem como o das capacidades ociosas dos seus territórios - é o vetor fundamental de direcionamento dos Investimentos Estrangeiros Diretos, os quais revelam a arquitetura de interesses econômicos entre os chefes de Estado africanos e o resto do mundo, para além da China.

Palavras-chave: África. Formação socioespacial. Capacidades ociosas. Investimento Estrangeiro Direto. Desenvolvimento.

\section{BEYOND CHINA: IDLE CAPACITY AND FOREIGN DIRECT INVESTMENT IN AFRICAN SOCIO-SPATIAL FORMATIONS IN THE EARLY 21ST CENTURY}

\begin{abstract}
The recent growth of most African economies has led to the development of numerous analyzes that conditioned the phenomenon in question to the Chinese economic dynamism. However, in addition to the evident influence of the Asian country - which operates in Africa through bilateral agreements, loans and different types of investments - it is also necessary to raise what are the specific conditions of the productive forces of the 54 African socio-spatial formations today. The understanding of these specificities - as well as the idle capacities of their territories - is the primary vector for directing the Foreign Direct Investments, which reveal the architecture of economic interests between African heads of state and the rest of the world, beyond China.
\end{abstract}

Keywords: Africa. Socio-spatial formation. Idle capacities. Foreign Direct Investment. Development.

\section{MÁS ALLÁ DE CHINA: CAPACIDAD SANTA E INVERSIÓN EXTRANJERA DIRECTA EN FORMACIONES SOCIOESPACIALES AFRICANAS EN EL PRIMER SIGLO XXI}

Resumen: El reciente crecimiento de la mayoría de las economías africanas ha llevado a la elaboración de numerosos análisis que condicionaron el fenómeno en cuestión al dinamismo económico chino. Sin embargo, además de la evidente influencia del país asiático - que opera en África a través de acuerdos bilaterales, préstamos y diferentes tipos de inversiones -, también es necesario plantear cuáles son las condiciones específicas para el desarrollo de las fuerzas productivas de las 54 formaciones socioespaciales africanas en la actualidad. La comprensión de estas especificidades, así como las capacidades ociosas de sus territorios, es el vector fundamental para dirigir las inversiones extranjeras directas, que revelan la arquitectura de los intereses económicos entre los jefes de estado africanos y el resto del mundo, más allá de China.

Palabras clave: África. Formación socioespacial. Capacidades ociosas. Inversión Extranjera Directa. Desarrollo.

\footnotetext{
${ }^{1}$ London School of Economics and Political Science, Latin American and Caribbean Centre, Londres, Reino Unido, kauegeo@gmail.com / k.lopes-dos-santos@lse.ac.uk / https://orcid.org/0000-0001$\underline{9996-1079}$
} 


\section{INTRODUÇÃO}

Em agosto de 2018, Xi Jinping prometeu direcionar 60 bilhões de dólares aos países africanos por meio de assistências, investimentos e empréstimos. A ação do presidente da República Popular da China (RPC) foi amplamente divulgada por algumas das principais agências de notícias do mundo (Reuters, AFP, EFE), dando espaço à múltiplas interpretações sobre os interesses econômicos e políticos que vem sendo consolidados na relação entre Beijing e os chefes de Estados africanos.

Nos últimos anos, tal relação tornou-se um tema constantemente abordado também nas ciências humanas do mundo ocidental, especialmente por parte de economistas e cientistas políticos. As argumentações por eles construídas vem sendo publicadas em reportagens, artigos e livros e buscam identificar os possíveis rumos do continente africano no século XXI. De acordo com grande parte dessas publicações - as quais não se fartam de lançar mão do tom de denúncia -, a África encontra-se submetida a uma espécie de neocolonialismo por parte do governo chinês.

A relação entre a China e a África não é recente. Alguns territórios africanos principalmente aqueles banhados pelo Oceano Índico - mantém relações comerciais seculares com o país asiático, de modo que alguns documentos historiográficos apontam que mais de 60 embarcações viajaram de Beijing até a África Oriental durante a dinastia Ming, entre os anos de 1418 e 1433 (BRAUTIGAM, 2009). Contudo, a presença chinesa no continente se intensificou significativamente a partir do final do século XX. A estratégia internacional da RPC viabilizou-se por meio de uma política denominada Go Out. Nas palavras do geógrafo estadunidense Richard Grant:

Em 1999, o governo chinês iniciou a política do Go Out para encorajar companhias chinesas a investir no exterior e isso tornou-se o pilar da própria estratégia de desenvolvimento da China após 2001. Essa política incentivou firmas chinesas a fazer negócios no exterior, ao passo que as tornava mais competitivas mediante a aquisição de ativos estratégicos, assegurando acesso a recursos naturais e estabelecendo novos mercados para as exportações chinesas. Inicialmente, grandes companhias estatais de construção lideraram o processo, mas, recentemente, firmas privadas em todos os setores têm participado (GRANT, 2015: 289, tradução do autor).

O sucesso dessa estratégia verificou-se pelo fato de que, na atualidade, a China tornou-se o maior parceiro comercial do continente africano, além de ser um de seus maiores investidores. Essa relação foi gradativamente institucionalizada por 
meio do Forum China Africa Cooperation (FOCAC), realizado pela primeira vez em 2006, na cidade de Beijing. É importante notar que, nessas relações - que são estabelecidas por meio de acordos bilaterais -, a RPC manifesta uma política de não interferência nos assuntos domésticos dos países com que coopera, respeitando o princípio da soberania territorial. De modo geral, pode-se dizer que os principais comprometimentos dos chineses com relação ao países africanos nos últimos anos tem sido: intensificar os investimentos e ajudas financeiras, intensificar o comércio, fortalecer cooperações em torno do desenvolvimento econômico, facilitar perdões de dívidas e construir uma ampla gama de infraestruturas, sobretudo de transporte, energia, além de escolas e hospitais (GRANT, 2015).

Diante de tantos comprometimentos de ordem econômica, política e social compreende-se o fascínio que a temática China-África possa despertar. Contudo, este artigo não objetiva engrossar as análises que vêm sendo produzidas sobre o assunto. A bem da verdade, o objetivo aqui é entender em que medida o atual momento pelo qual passam os países do continente em questão - marcados por expressivas taxas de crescimento econômico - pode ser produto de uma combinação de fatores construídos historicamente que vão além das relações com a China.

Os 54 países africanos representam materialmente múltiplas formas de desenvolvimento das forças produtivas, ainda que os Estados imperialistas do Norte Global tenham tentado - pela força militar em fins do século XIX e por imposições financeiras em fins do século $X X$ - reduzir o papel desses territórios à exportadores de commodities na Divisão Internacional do Trabalho.

Neste texto, parte-se da premissa conceitual de que a África é formada por 54 formações socioespaciais. Desenvolvido na década de 1970, esse conceito é apontado como uma das principais contribuições do geógrafo brasileiro Milton Santos à ciência geográfica (MAMIGONIAN, 1996). Tal contribuição, por sua vez, deriva do conceito marxista de formação econômico-social, que se propõe a estabelecer uma leitura histórica sobre as especificidades do desenvolvimento dos modos de produção pelo mundo, viabilizando, assim, uma análise da evolução diferencial das sociedades e de suas economias (SANTOS, 1977). Milton Santos sugeriu, a partir de então, 
incorporar a noção de espaço como variável fundamental para compreender tal evolução diferencial.

Diante das referidas especificidades econômicas de cada país, surgem também as suas limitações - ou pontos de estrangulamento - no que tange o desenvolvimento de suas forças produtivas. Essas limitações serão aqui denominadas capacidades ociosas, termo desenvolvido pelo economista brasileiro Ignacio Rangel nas décadas de 1970 e 1980 (RANGEL, 1986; MAMIGONIAN, 1987). Se analisadas e problematizadas com rigor, as capacidades ociosas podem servir como matériaprima estruturadora de robustas políticas de desenvolvimento para os países africanos. Tais políticas, por sua vez, devem ser devidamente articulada às possibilidades de investimentos, especialmente investimentos estrangeiros diretos, que viabilizem o crescimento econômico de médio e longo prazo e permitam potencialmente a melhoria da qualidade de vida da população.

\section{O DINAMISMO ECONÔMICO RECENTE DAS FORMAÇÕES SOCIOESPACIAIS AFRICANAS: DO PESSIMISMO DO FINAL DO SÉCULO XX AO OTIMISMO DO INÍCIO DO SÉCULO XXI}

Em setembro de 1992, a revista inglesa Time Magazine estampava em sua capa a fotografia de um menino somali vitimado pela fome em um campo de refugiados no Quênia. Junta à manchete $A$ agonia da África, essa imagem impactante era um convite a leitura de 16 páginas sobre a fome, as secas, a miséria, a superpopulação, a disseminação de doenças, a burocracia e a as práticas regulares de corrupção dos governos dos países do continente (TIME MAGAZINE, 1992).

Passadas duas décadas, em outubro de 2012, a mesma revista publicava em sua capa a imagem de um grande baobá em meio urbano. Nessa ocasião, contudo, a manchete intitulava: O crescimento da África. Pontuando os numerosos problemas de ordem social, econômica e política ainda presentes no continente, o objetivo da publicação era o de revelar as transformações e o dinamismo pelo qual grande parte dos países africanos passaram a viver no início do século XXI, marcados por uma modernização - ainda que seletiva - das forças produtivas, e pela desburocratização 
das relações de produção, para além da expansão da urbanização, da tendência a estabilidade política e da redução dos índices de pobreza. O subtítulo da mesma reportagem era [A África] é a próxima casa de força econômica do mundo (TIME MAGAZINE, 2012).

Esse otimismo contemporâneo tem sido revelado por meio das elevadas taxas de crescimento real do Produto Interno Bruto (PIB) dos países do continente. $\mathrm{Na}$ média, a África apresentou um crescimento de 4,6\% ao longo dos primeiros 18 anos do século XXI. É verdade que, quando decupada, essa média revela grandes variações - como o pico de 6,8\% em 2012 e a baixa de 2,6\% em 2016 (conferir Gráfico $01)$ - que estão relacionadas principalmente às flutuações no mercado internacional de commodities. A Nigéria, por exemplo, chegou a crescer 11,3\% em 2010 quando o preço do barril do petróleo - principal produto de exportação do país - chegou aos 60,8 dólares Contudo, em 2016, o país registrou crescimento negativo $(-1,6 \%)$ quando o preço do barril caiu para 40,6 dólares (conferir Gráfico 02) (FMI, 2019; OPEP, 2019).

\section{Gráfico 01: Crescimento do PIB no continente africano entre 1991 e 2019 (em \%)}

8

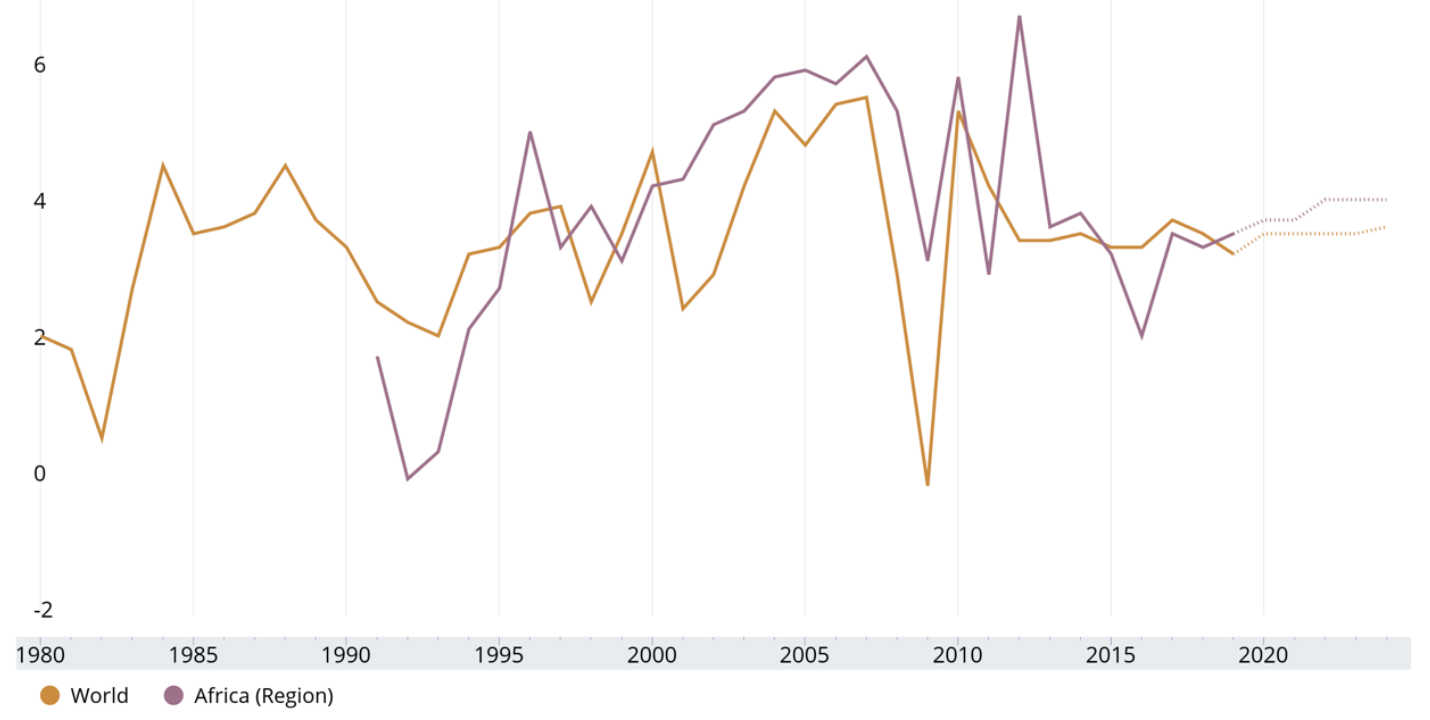

Fonte: FMI, 2019. 
Gráfico 02: Crescimento do PIB na Nigéria entre 1991 e 2019 (em \%)

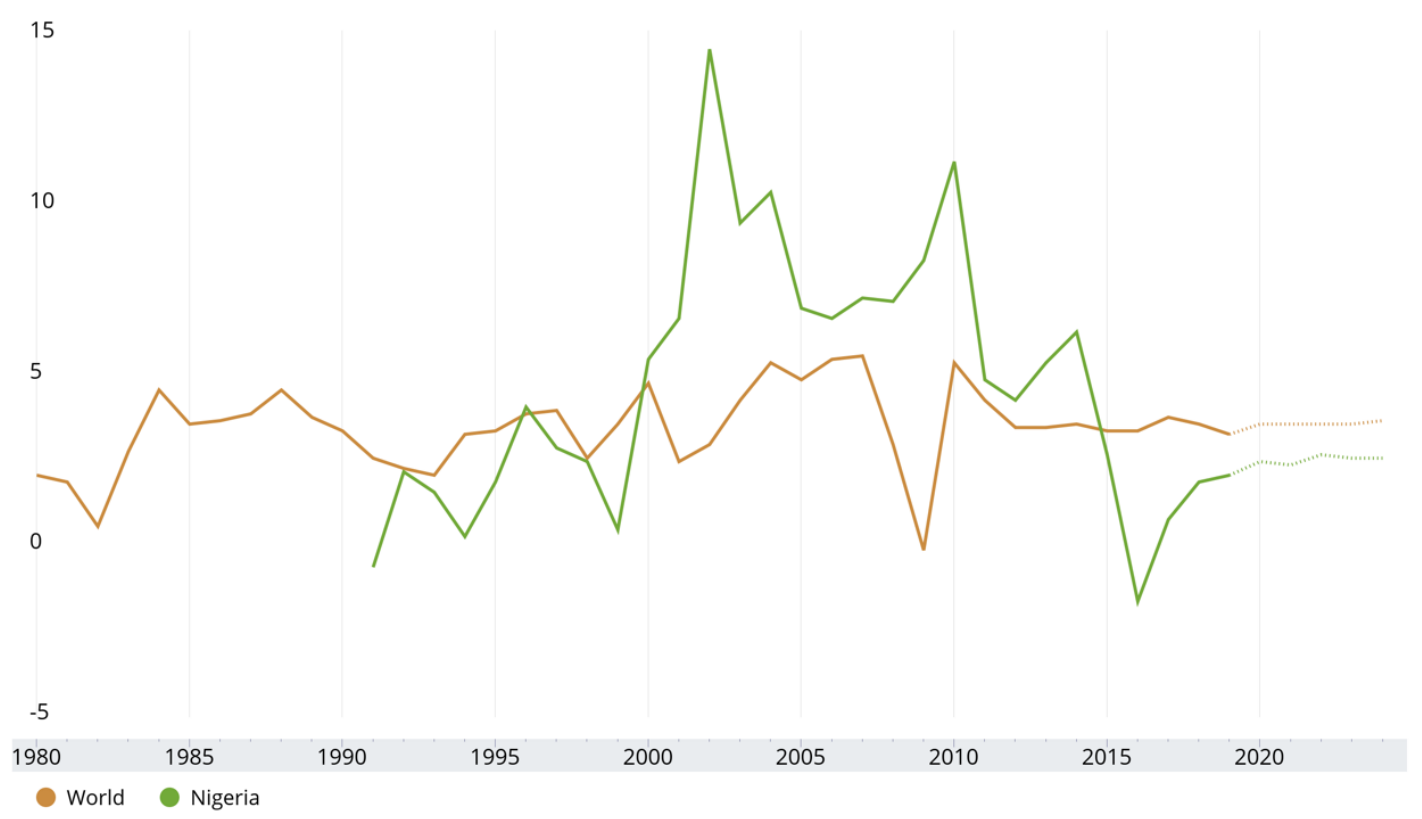

Fonte: FMI, 2019.

Em termos gerais, a atual análise da conjuntura econômica africana difere diametralmente daquela que era feita no final do século XX. Naquela época, há aproximadamente 30 anos, acadêmicos de diferentes áreas das ciências humanas e sociais buscavam analisar aquilo que o economista egípcio Samir Amin havia denominado como o fracasso econômico dos países africanos (AMIN, 1992). De forma geral, esse fracasso foi justificado por: Estados nacionais que acumularam vultosas dívidas externas, baixa produtividade nos setores primários e secundários da economia, graves problemas de ordem socioeconômica (desemprego, pobreza e fome), para além de instabilidade políticas diversas, que eram alimentadas por sucessivos golpes de Estados e guerras civis. Mas como foi construído o cenário pessimista da economia africana de fins do século XX? Para além disso, como se deu a sua transformação no início do século XXI?

Em um esforço de elaboração de uma breve cronologia da economia do continente, pode-se dizer que, a luz dos processos de independência do jugo colonial europeu em meados do século XX, a grande maioria dos governos das nascentes formações socioespaciais africanas incluíram em suas agendas a implementação da 
política de industrialização por substituição de importações. Os objetivos dessa política estiveram associados à modernização das forças produtivas, as quais ainda se encontravam estruturalmente organizadas em função da produção de commodities minerais e agrícolas. Assim, ao viabilizar a industrialização buscou-se diversificar a estrutura produtiva dos respectivos territórios, absorver bens de capital e tecnologia dos países desenvolvidos, gerar empregos nas cidades, modernizar o campo e reduzir a vulnerabilidade externa, que era ainda marcada por uma balança comercial tendencialmente deficitária. Segundo o economista nigeriano Adebayo Adedeji:

Os governos africanos realmente desejavam, o quanto antes, elevar o grau da independência adquirida e, como consequência, melhorar o nível de vida do seu povo, através do aumento nos rendimentos e da implantação dos serviços sociais, bem como das infraestruturas de base. Todos consideravam praticamente um fato consumado e incorporado que a planificação econômica constituísse o meio mais racional, com vistas à realização destas mudanças. Se, antes da emancipação da África, os teóricos do desenvolvimento se haviam mostrado divididos quanto à pertinência e aos méritos dos planos, no imediato posterior à independência, em contrapartida, os planejadores impuseram -se de forma contundente: após a dissolução dos regimes coloniais, os governos foram prontamente conduzidos a apresentarem, cada qual, um plano concebido para responder ao que se considerava como exigências ao desenvolvimento, do país e do seu povo (ADEDEJI, 2010: 471).

Implementados fundamentalmente nas décadas de 1960 e 1970, esses planos tiveram seus financiamentos nas arrecadações tributárias e nos empréstimos estrangeiros, especialmente os obtidos em organizações multilaterais e em países como os Estados Unidos e a União Soviética. Nesse contexto, o caráter protecionista da política econômica dos países africanos ganhou força e, segundo o economista malaui Thandika Mkandawire:

O Estado deveria alimentar as indústrias nascentes com toda uma bateria de medidas políticas: tarifas, capital barato, restrições quantitativas sobre importações competitivas, subsídios em termos de infraestrutura barata, serviços e treinamento de mão-de-obra [...] (MKANDAWIRE, 1992: 91, tradução do autor).

Entre 1960 e 1975, registrou-se um período no qual a indústria africana cresceu em média $7,5 \%$, percentual semelhante ao observado em regiões como a América Latina e o Sudeste Asiático. ${ }^{2}$ A politica de substituição de importações trouxe de fato

\footnotetext{
${ }^{2}$ Apesar das elevadas taxas de crescimento, Mkandawire aponta também para os seguintes fatos a serem levados em consideração no período: i) o valor agregado dos bens industrializados era baixo (relativo sobretudo à produção de bens de consumo e bens intermediários); ii) havia uma grande disparidade interna no continente, de modo que Nigéria, Egito, Argélia e Líbia responderam juntos por $53 \%$ da produção industrial africana, enquanto os 27 países menos industrializados responderam
} 
uma diversificação das forças produtivas (em especial com o desenvolvimento da indústria de bens intermediários e bens de consumo não-duráveis) e a modernização das infraestruturas de energia (a partir da construção de hidrelétricas e termoelétricas) e circulação (a partir da construção de rodovias). Grande parte dos governos africanos realizaram investimentos na educação e na saúde, especialmente nos espaços urbanos, visando a melhoria das condições de vida da população e o desenvolvimento de quadros técnico-administrativos nacionais.

No entanto, nas décadas seguintes - 1980 e 1990 - os países do continente experimentaram um forte processo recessão decorrente das crises do petróleo de 1973 e 1979 e das imposições regulatórias proveniente dos Estados Unidos (via Fundo Monetário Internacional e Banco Mundial). Nesse contexto, a queda no preço das commodities no mercado externo reduziu significativamente as arrecadações dos Estados. Desse fato configurou-se o aumento dos desequilíbrios orçamentários com o aumento do déficit público, já que houve a redução das entradas. A dívida externa - que estava na média dos $20 \%$ do PIB dos países africanos em meados da década de 1970 - entrou em uma trajetória ascendente até alcançar a média de aproximadamente $110 \%$ do valor do PIB em meados da década de 1990 (FMI, 2019).

Assim, esse endividamento reduziu a capacidade de investimento dos governos, gerando uma queda expressiva da produtividade na agricultura, na mineração e na indústria, acompanhada pela inflação, pelo desemprego e pelo câmbio sobrevalorizado (congelado), que ampliou a atuação do mercado paralelo em muitos países. Desse modo, configurou-se aquilo que Samir Amin denominou como fracasso econômico. Somada a essa conjuntura problemática, as secas da região do Sahel, a disseminação de doenças infectocontagiosas e algumas guerras civis ampliaram o cenário de tragédia econômica, política e social de algumas formações socioespaciais.

Visando atrair investimentos produtivos e liquidar a dívida externa, a alternativa encontrada por muitos governos foi recorrer aos Planos de Ajuste Estrutural (PAE) coordenados pelo Fundo Monetário Internacional (FMI). Estruturados sob a égide do neoliberalismo, esses planos previam principalmente: a redução dos gastos públicos; o congelamento de salários; o aumento de taxas de juros; a desvalorização cambial; as privatizações e a abertura dos mercados para a economia mundial. 50

juntos por menos de $1 \%$ da produção industrial e; iii) a instabilidade desse crescimento dentro do período considerado esteve fortemente relacionada ao preço das commodities no mercado internacional (MKANDAWIRE, 1992). 
enfraquecimento econômico da União Soviética na década de 1980 também significou a redução do poder de negociação dos líderes africanos diante das possibilidades de obtenção de empréstimos e acordos comerciais internacionais (MKANDAWIRE, 1992; FOSU E ARYEETEY, 2008; KILLICK, 2010).

Com a implementação do PAE, conquistou-se gradualmente a estabilidade fiscal e monetária, ao mesmo tempo que a abertura dos mercados nacionais garantiram a entrada dos capitais externos ao longo das décadas de 1980 e 1990. Tais capitais estiveram condicionados as atividades de exportação, em especial à extração de recursos minerais e energéticos. Os investimentos concentraram-se sobretudo em infraestruturas de energia e circulação na medida em que estas serviam à produção e à comercialização de commodities para o mercado internacional. Nesse momento, o projeto de industrialização por substituição de importações já havia sido abortado pela maior parte dos países africanos, tornando suas economias altamente dependentes da importação de bens manufaturados. Com exceção da África do Sul, do Egito e da Argélia - que conseguiram diversificar no médio e longo prazo a estrutura produtiva por meio da industrialização -, o que se observou no restante da África foi uma gradativa desindustrialização, de modo que, em 2005, a participação do continente na produção mundial de manufaturas era de apenas 0,3\% (PAGE, 2012).

Em certa medida, o PAE e a elevação no preço das commodities no mercado internacional - estimulada pelo crescimento industrial da China e dos Tigres Asiáticos - tiveram um papel importante na estabilização e crescimento econômico da grande maioria dos países africanos nas primeiras décadas do século XXI. Contudo, nesse processo, não se pode negligenciar o papel dos próprios chefes de Estado e de seus quadros técnicos em sua habilidade de negociação e conformação de políticas econômicas voltadas aos interesses nacionais.

Associado a esse processo de crescimento econômico, o aumento da estabilidade política e a melhoria das condições de vida da população colaboraram em tornar os países africanos importantes destinações dos Investimentos Estrangeiros Diretos. De acordo com o economista estadunidense Noah Smith: 
Várias outras tendências tornam o investimento na África uma perspectiva mais tentadora. As taxas de alfabetização aumentaram rapidamente. As mortes por malária foram reduzidas quase pela metade desde a virada do século, ao passo que a fome e a mortalidade infantil também caíram. Uma população mais saudável e mais instruída está muito melhor preparada para ler instruções, absorver informações e comparecer ao trabalho de forma consistente. Enquanto isso, o aumento da alfabetização e do acesso à Internet está revelando vastos conjuntos de talentos africanos anteriormente ocultos. A governança também está melhorando. As grandes guerras dos anos 1990 e 2000 terminaram na maior parte. A democracia está proliferando, à medida que golpes e autocratas fortes se tornam mais raros. As medidas de governança melhoraram. Um governo mais estável significa um ambiente mais estável para empresas que desejam investir. Não há escassez de potenciais destinos de investimento. O continente tem 54 países, ostentando uma variedade estonteante de instituições, idiomas e vantagens comparativas (SMITH, 2018: s/p, tradução do autor).

Como aponta Smith em sua análise sobre a melhoria das condições de investimento na África, o universo oferecido é múltiplo e condiz à diversidade de unidades políticas para negociação. Assim, antes de analisar a geografia desses investimentos, interessa aqui compreender mais as especificidades das formações socioespaciais do continente.

\section{AS ESPECIFICIDADES DAS FORMAÇÕES SOCIOESPACIAIS AFRICANAS, ESTRUTURAS PRODUTIVAS E CAPACIDADES OCIOSAS}

O esforço de traçar um histórico acerca da economia africana é produto de numerosas comparações, as quais permitem identificar algumas semelhanças nas políticas econômicas implementadas pelos países do continente em sua história póscolonial.

Ao mesmo tempo que a tarefa de identificar as semelhanças do desempenho econômico desses países nas últimas décadas pode auxiliar na compreensão de muitas dinâmicas regionais e planetárias, ela pode também induzir ao erro por promover análises generalistas. Desse modo, torna-se mister uma abordagem que considere as especificidades das formações socioespaciais africanas haja visto que o modo de produção se organiza de diferentes formas em cada país, revelando arranjos 
específicos e historicamente construídos entre as forças produtivas e as relações de produção (SANTOS, 1977).

O geógrafo francês André Cholley explicou a importância que a noção de combinação tem para a análise geográfica (CHOLLEY, 1964; MAMIGONIAN, 2003). Dada uma determinada unidade política - ou uma formação socioespacial - é possível levantar numerosas variáveis de ordem natural, social, cultural, econômica e política que dão visibilidade a uma leitura mais complexa do espaço, sobretudo se essa leitura estiver posicionada em uma perspectiva dialética do processo histórico.

Em termos da riqueza gerada em cada país africano, as distinções são perceptíveis quando se compara o PIB dos mesmos. As maiores economias africanas em 2018 foram: Nigéria (397,27 bilhões de dólares), África do Sul (368,14 bilhões de dólares), Egito (249,56 bilhões de dólares) e Argélia (180,44 bilhões de dólares). Em contrapartida, os países com as piores performances - com o PIB abaixo dos 5 bilhões de dólares no mesmo ano - ocorrem em pequenos países insulares (São Tomé e Príncipe, Cabo Verde, Seychelles e Comores) e costeiros (Libéria, Serra Leoa, Guiné Bissau e Gâmbia), ou naqueles sem saída para o mar (Republica Centro Africana, Sudão do Sul, Burundi, Lesoto e Eswatini) e que são caracterizados pela escassez de recursos naturais em seus territórios ou mesmo pela instabilidade politica (FMI, 2019).

Dadas as condições econômicas específicas historicamente forjadas em cada uma dessas formações socioespaciais, o que se observa na atualidade são estruturas produtivas centradas fundamentalmente na exploração de recursos naturais (minerais e energéticos), na agricultura (de subsistência e comercial) ou na pecuária.

As condições físico-naturais do continente permitiram a exploração de variados recursos ao longo do tempo. Os relatos de geógrafos árabes do século XII já mencionavam a exploração de ouro na África Ocidental, em localidades onde hoje estão os territórios de Gana e Guiné (DAVIDSON, 1985). Atualmente, estima-se que a África possua: $42 \%$ da bauxita mundial; $35 \%$ do urânio; $42 \%$ do ouro; $57 \%$ do cobalto; $39 \%$ do manganês; $73 \%$ da platina; $88 \%$ dos diamantes; $10 \%$ do petróleo e; $5 \%$ do cobre (GRANT, 2015). Evidentemente, a distribuição desses recursos se dá de maneira desigual, como revela a llustração 1. 


\section{Ilustração 01: Croqui cartografico dos setores produtivos nas formações} socioespaciais africanas (2018)

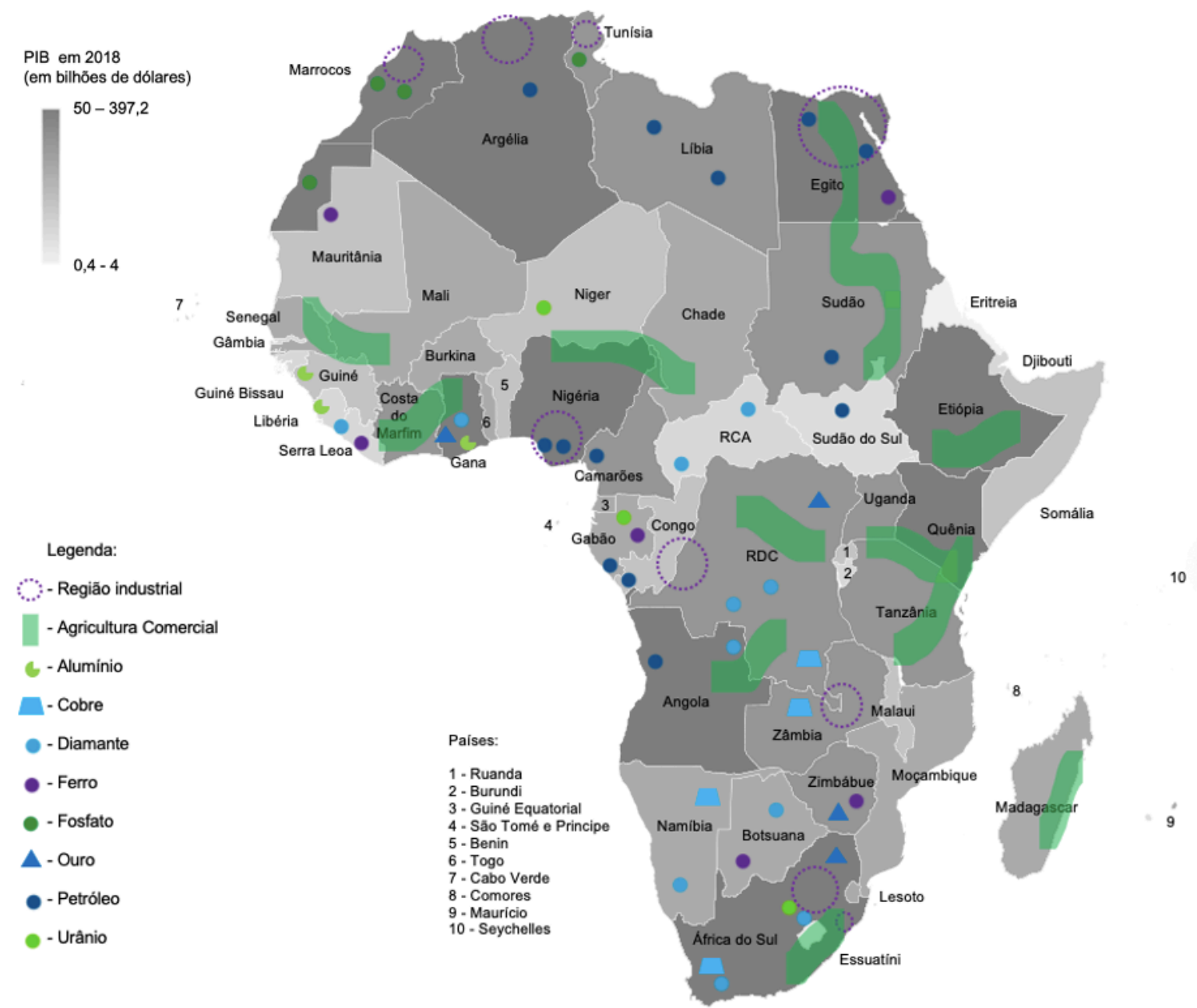

Fonte: Elaboração do autor com base CIA, 2019.

Pode-se observar que alguns territórios possuem uma significativa diversidade de recursos minerais para serem explorados economicamente, como África do Sul, Botsuana, Namíbia, Gabão e Gana. Essa diversidade depende das condições geológicas - ocorrendo principalmente em estruturas cristalinas - e sua exploração e comercialização asseguram uma menor vulnerabilidade econômica nesses países, dado que representa uma maior diversidade da estrutura produtiva. A África do Sul é o país com maior diversidade de recursos em seu território, como ouro (umas das maiores produtoras do mundo do recurso), cobre, diamante, carvão e urânio.

O petróleo, por sua vez, é explorado por países como Nigéria, Angola, Argélia, 
Líbia (todos os quatro membros africanos na OPEP), além de Egito, Sudão, Congo e Gabão. Há também uma intensa atividade de extração madeireira nas áreas de florestas equatorial e tropical, sobretudo nas formações vegetais nativas de países como República Democrática do Congo (RDC), Uganda, Burundi, Ruanda, Congo, Gabão, Guiné Equatorial e Camarões.

As condições físico-naturais ainda possuem influência concreta na agropecuária, seja aquela praticada para a subsistência, seja aquela praticada para o mercado (nacional ou estrangeiro). Na maior parte do continente, a modernização da agricultura (especialmente de subsistência) não ocorreu apesar de ter sido uma das preocupações das políticas de substituição de importações. Desse modo, as técnicas empregadas muitas vezes são rudimentares, pouco produtivas e geram a intensificação da erosão superficial do solo, colaborando para a ocorrência do processo de desertificação em áreas como o Sahel.

A agricultura comercial - especialmente aquela destinada à exportação - conta principalmente com o cultivo de gêneros tropicais, como algodão (Mali, Burkina Faso Chade, Sudão, Egito e Madagascar), cacau (Costa do Marfim, Gana, Nigéria, Camarões), amendoim e óleo de palma (Senegal Nigéria, Chade, Sudão, Congo e RDC), cana de açúcar (Quênia, Tanzânia, Madagascar e África do Sul) e café (Costa do Marfim, RCA, RDC, Angola, Quênia, Tanzânia, Uganda, Burundi, Ruanda, Madagascar e Etiópia).

A industrialização, por sua vez, foi uma experiência bem-sucedida em poucos países, como África do Sul, Egito e Argélia. Essas formações socioespaciais conseguiram desenvolver parques industriais diversificados, marcados pela presença de empresas nacionais (de capital estatal e/ou privado) e estrangeiras nos subsetores de bens de consumo, bens intermediários e bens de capital. Na África do Sul, os centros industriais estão nas áreas urbanas de Johanesburgo, Durban e Cidade de Cabo. Já no Egito, eles estão entre as cidades de Cairo e Alexandria e, na Argélia, estão concentrados entorno da capital Argel. Os produtos dessas indústrias podem ser encontrados em mercados e supermercados das cidades de todo o continente, revelando uma importante dinâmica comercial entre as formações socioespaciais africanas. 
Nos demais países, pode-se observar a atuação de dois tipos de indústria: aquelas de bens intermediários que são altamente capitalizadas - formadas pelo capital nacional estatal ou pelo capital estrangeiro - que se dedicam ao processamento de recursos naturais (e agrícolas) vinculadas às exportações e; aquelas de bens de consumo não duráveis que possuem baixo nível de capitalização e produzem alimentos, fármacos e roupas para um mercado regional ou nacional, como farinhas, pães, biscoitos, sucos, etc. Outros importantes centros urbanoindustriais estão nas Lagos (Nigéria), Kinshasa (RDC), Brazaville (Congo), Ndola (Zâmbia), Casablanca e Rabat (Marrocos) e Tunis (Tunísia).

De modo geral, apesar do crescimento econômico africano ao longo dos primeiros anos do século XXI, existem ainda alguns entraves ao desenvolvimento das forças produtivas na maior parte das formações socioespaciais do continente. Podese entender esses entraves como capacidades ociosas (RANGEL, 1986), que representam aspectos direta ou indiretamente relacionados à economia e que podem ser solucionados através de investimentos (nacionais ou estrangeiro, privados ou públicos).

De acordo com o economista estadunidense John Page (2012), existem três aspectos centrais relacionados às economias africanas que precisam ser desenvolvidos: as infraestruturas, a integração regional no continente e a qualificação da mão-de-obra (PAGE, 2012).

No âmbito das infraestruturas de circulação, existe a necessidade de melhorar a qualidade e aumentar a quantidade de quilômetros construídos de rodovias e ferrovias em praticamente todos os territórios. A África do Sul desponta como o país que possui a maior quilometragem de rodovias pavimentadas e não pavimentadas (747 mil km) e o mesmo ocorre com a quilometragem de ferrovias (20 mil km) (ClA, 2019). Com exceção dessa formação socioespacial, predomina um padrão de infraestrutura de circulação dentro do continente no qual rodovias e ferrovias de maior eficiência estão à serviço apenas do escoamento das commodities minerais e agrícolas, padrão esse herdado da época colonial.

Nos dias de hoje existe também a necessidade de dinamizar e, eventualmente, ampliar as infraestruturas de distribuição, em especial os portos marítimos e os portos 
secos. A importância das zonas portuárias decorre do fato de que elas não apenas devem lidar com a distribuição dos fluxo de importação e exportação de um país, mas devem também, em muitos casos, distribuir o fluxo do comércio internacional dos 16 países do continente que não possuem saída para o mar (Lesoto, Eswatini, Botsuana, Zimbábue, Zâmbia, Malaui, Burundi, Ruanda, Uganda, Sudão do Sul, Etiópia, RCA, Chade, Níger, Mali, Burkina Faso).

Para além das infraestruturas de circulação e distribuição, outra capacidade ociosa na África são as infraestruturas de energia elétrica. Mesmo com os investimentos na construção de barragens e usinas hidrelétricas nos primeiros anos pós-independência, são ainda comuns os apagões na maior parte dos países da África ao Sul do Saara. Efetivamente, esse dado aumenta o custo produtivo de muitos empreendimentos, que acabam lançando mão de geradores próprios. Cálculos de empresas que investem no continente apontam que Nigéria, Guiné e Gâmbia são os países que registram com maior frequência problemas na infraestrutura energética: cortes na transmissão de energia ocorrem praticamente todos os dias do ano na Nigéria e em cerca de 200 dias por ano na Guiné e no Gâmbia (RAMACHANDRAN, 2012).

Page também chama a atenção com relação à questão da integração regional (2012). Atualmente, os principais parceiros comerciais dos países africanos são a China, os Estados Unidos, alguns países da Europa (França, Reino Unido, Holanda, Bélgica, Alemanha e Portugal) e asiáticos (Índia, Tigres Asiáticos e Novos Tigres Asiáticos). Esse dado econômico aparentemente desestimula o desenvolvimento de politicas de integração, as quais poderiam ser traduzidas no bom funcionamento dos blocos econômicos regionais já existentes no continente. ${ }^{3}$ Diversos aspectos dificultam essa integração regional, como: a precariedade das infraestruturas de circulação e distribuição, mencionada acima; os desequilíbrios regionais entre os países, que dificultam a elaboração de acordos de livre circulação (de mercadoria, capital e pessoas) face os interesses nacionais dos Estados com menos recursos, dentre outros (PAGE, 2012; SANTOS, 2017).

Contudo, em março de 2018, na cidade de Kigali (capital Uganda), 44 das 54 formações socioespaciais africanas que integram a União Africana assinaram um

\footnotetext{
${ }^{3}$ Entre os blocos e comunidades econômicas regionais na África destacam-se: Arab Maghred Union (AMU), The Community of Sahel-Saharan States (CEN-SAD), Common Market for Eastern and Southern Africa (COMESA), East African Community (EAC), Economic Community of Central African States (ECCAS), Economic Community of West African States (ECOWAS), Intergovernmental Authority on Development (IGAD) e a Southern African Development Community (SADC) (UNECA, 2019).
} 
acordo estabelecendo a African Continental Free Trade Area (AfCFTA). Caso seja bem-sucedido - em termos de ratificação e implementação - este será o maior acordo comercial desde a fundação da Organização Mundial do Comércio (em 1995), uma vez que almeja a criação de um mercado único para mercadorias, serviços e circulação de pessoas. De acordo com a UNCTAD:

O plano é estabelecer e negociar um protocolo comercial continental em bens que, embora em estágio avançado [na cadeia produtiva], ainda precisam ser concluídos. O objetivo é cortar 90 por cento das tarifas de sua média atual de 6,1 por cento para eventualmente zero e abordar a multiplicidade de barreiras não-tarifárias, como a infraestrutura deficiente e os postos de fronteira ineficientes, que muitas vezes são a barreira dominante e custo para a negociação no continente. Protocolos sobre direitos de propriedade intelectual, investimento e concorrência serão adicionados ao acordo geral mais tarde (UNCTAD, 2018: 43, tradução do autor).

Os esforços de integração do continente empregados pelos seus atuais chefes de Estado, reforçam a necessidade de cooperação comercial entre os países africanos como mecanismo de diversificar seus vínculos comerciais.

Por fim, a terceira maior capacidade ociosa do continente, na perspectiva de Page, está na qualificação da mão de obra. Por mais que tenha sido registrados melhorias nas taxas de alfabetização nos últimos anos, ainda existe uma necessidade concreta de investir em instituições escolares, universitárias e de formação técnica (PAGE, 2012).

De modo geral, deve-se reforçar que os fatores mencionados por Page - e que neste artigo são entendidos como capacidades ociosas - estão presentes em diferentes estágios segundo o desenvolvimento das forças produtivas em cada formação socioespacial africana. Diante do contexto de crescimento econômico de grande parte dos países do continente no início do século XXI - processo que também expõe as limitações e os desafios desses territórios - entende-se os Investimentos Estrangeiros Diretos desempenham um papel importante na internacionalização e eventual diversificação da estrutura produtiva nas economias africanas. Assim, interessa agora compreender a geografia desses investimentos. 


\section{A GEOGRAFIA DO IED NAS FORMAÇÕES SOCIOESPACIAIS AFRICANAS NO INÍCIO DO SÉCULO XXI}

Analisar a geografia dos Investimentos Estrangeiros Diretos (IED) na África é uma tarefa importante na medida que permite compreender o grau de atração que as forças produtivas dos países africanos desempenham na economia internacional no que tange investimentos de médio e longo prazo. Um olhar atento à essa geografia permite evidenciar também as numerosas assimetrias internas, repelindo às análises generalistas produzidas sobre o dinamismo econômico do continente.

Segundo a OCDE, o Investimento Estrangeiro Direto:

[...] é uma categoria de investimento transfronteiriço na qual um investidor residente numa economia estabelece um interesse [empreendimento] duradouro e com um grau significativo de influência sobre uma empresa residente em outra economia [país]. A propriedade de $10 \%$ ou mais do poder de voto em uma empresa em uma economia por um investidor em outra economia é evidência de tal relacionamento. O IED é um elemento chave na integração econômica internacional porque cria ligações estáveis e duradouras entre as economias. O IED é um canal importante para a transferência de tecnologia entre países, promove o comércio internacional por meio do acesso a mercados estrangeiros e pode ser um veículo importante para o desenvolvimento econômico (OCDE, 2019, s/p, tradução do autor).

O IED não representa o único tipo de investimento externo absorvido pelos territórios africanos, de modo que as ajudas estrangeiras e os Investimentos Estrangeiros Indiretos (IEI) - que incluem investimentos em portfolio, financiamento de títulos e empréstimos bancários - representam os outros dois tipos de entrada de capital estrangeiro nos países do continente (ASIEDU, 2012, p.329). No entanto, como as ajudas estrangeiras se destinam fundamentalmente a resolução pontual de problemas de curto prazo e os IEI não estão presentes em grande parte dos países do continente - por estes não conseguirem captar recursos dos mercados internacionais de capital - os IED podem ser considerados como o principal investimento externo capaz de dinamizar as forças produtivas das formações socioespaciais de forma temporalmente consistente. 
No ano de 2017, a África absorveu 2,9\% dos Investimentos Estrangeiros Diretos (IED) do mundo, o que representou um montante de 41,8 bilhões de dólares. No mesmo ano, as demais regiões do Sul Global absorveram fatias significativamente maiores: a Ásia $33,3 \%$ (o equivalente a 475,8 bilhões de dólares) e a América Latina e Caribe 10,6\% (o equivalente a 151,3 bilhões de dólares) (UNCTAD, 2018). Esse dado ajuda a sustentar a tese de que, mesmo registrando expressivas taxas de crescimento do Produto Interno Bruto desde o início do século XXI, ainda existe a necessidade de solucionar as capacidades ociosas dos territórios africanos como forma de desenvolver suas forças produtivas e aumentar a competitividade internacional. Mesmo baixa se comparada a absorção dos IED na amostra do Sul Global, foi apenas no ano 2000 que esse tipo de investimento passou a superar os 10 bilhões de dólares anuais no continente africano (ASIEDU, 2012; UNCTAD, 2018).

O desenvolvimento particular das forças produtivas de cada formação socioespacial garantiu, contudo, uma marcada assimetria na distribuição das entradas de IED. Em 2017, os maiores fluxos destinaram-se ao Egito (7,4 bilhões de dólares), a Etiópia (3,6 bilhões) e a Nigéria (3,5 bilhões) (UNCTAD, 2018). Outras economias que atraíram fluxos significativos, superiores à 1 bilhão de dólares, foram: Gana, Marrocos, Moçambique, África do Sul, Zâmbia, RDC, Tanzânia, República do Congo, Gabão, Sudão e Argélia.

Em contrapartida, merecem destaque nessa análise os países que receberam os menores montantes de IED no ano analisado (abaixo de 500 milhões de dólares), como: Madagascar, Lesoto, Eswatini, Botswana, Zimbabwe, Malaui, Namíbia, Angola, Burundi, Ruanda, Somália, Eritreia, Sudão do Sul, Republica Centro Africana, Guiné Equatorial, Benin, Togo, Libéria, Burkina Faso, Mali, Mauritânia, Níger, Chade e Líbia (conferir llustração 2) (UNCTAD, 2018).

Estados Unidos, Reino Unido, França, China, África do Sul, Itália, Cingapura, Índia, Hong Kong (China) e Suíça representam o conjunto das 10 economias que mais investiram nos territórios africanos em forma de IED em 2017. O montante desses investimentos estocados pelos estadunidenses no continente alcançou ou 57 bilhões de dólares, seguido pelo Reino Unido (55 bilhões), França (49 bilhões) e China, que saltou de 16 bilhões em 2011 para 40 bilhões em 2017, umas das maiores e mais 
significativas taxas de crescimento de IED registradas no período em questão (UNCTAD, 2018).

\section{Ilustração 02: Croqui cartográfico da entrada do IED nas formações socioespaciais africanas em 2017 (em dólar)}

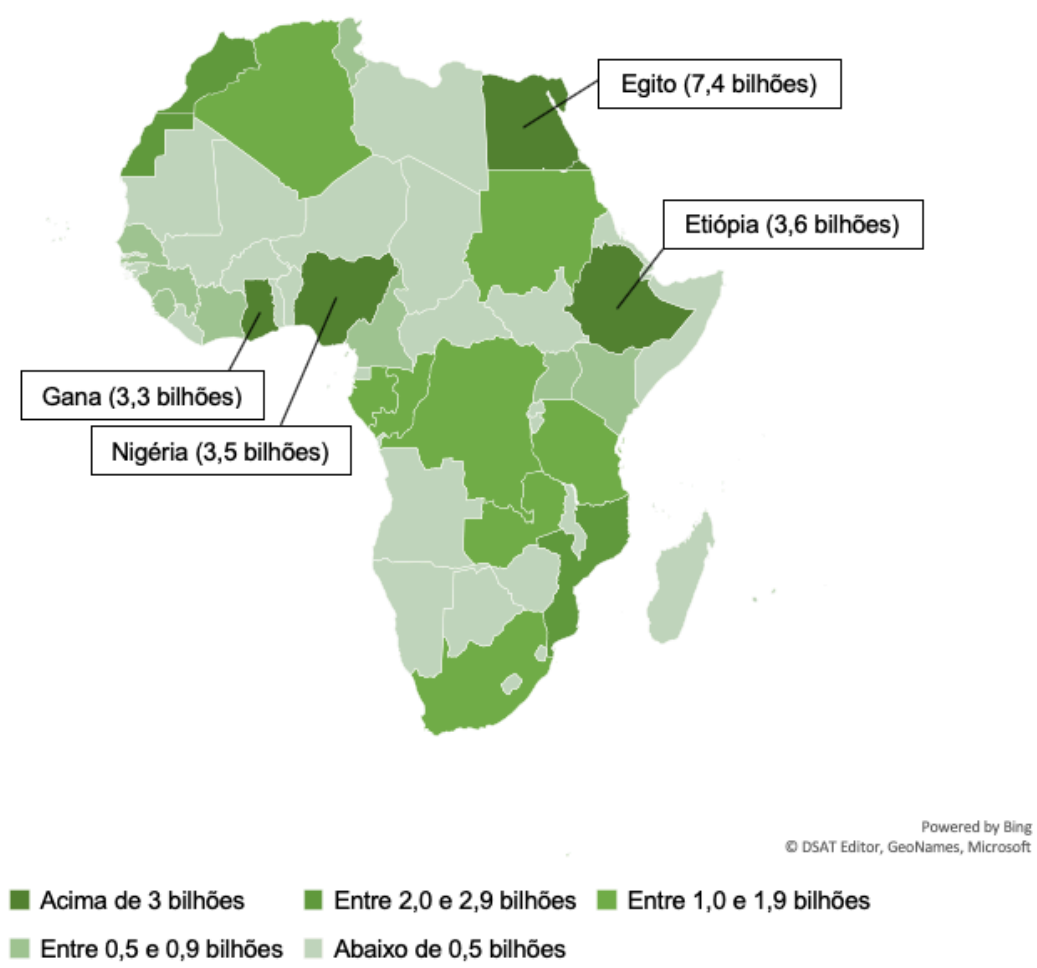

Fonte: Elaboração do autor com base em UNCTAD, 2018.

A expansão chinesa nos investimentos estrangeiros diretos salta aos olhos e é mais uma manifestação da agenda Sul-Sul que tal formação socioespacial asiática tem consolidado ao longo século XXI. Contudo, em termos de IED, a segunda maior economia mundial necessita ainda superar os investimentos estadunidenses, britânicos e franceses, algo que ocorrerá nos próximos anos se o país manter o padrão de crescimento atual.

Dentre os principais interesses relacionados aos IED implementados nas formações socioespaciais africanas, destacam-se projetos em variadas atividades: até o final de 2017 estavam alocados 10,5 bilhões de dólares em empreendimentos de extração/mineração de recursos minerais e energéticos (especialmente o petróleo); 21 bilhões na indústria química, têxtil, no processamento de minerais não-metálicos e 
na indústria de motores e equipamentos de transporte e; 53,6 bilhões alocados na construção de infraestruturas (de eletricidade, gás, água, construção civil, transporte, armazenamento e comunicação) além de serviços financeiros (UNCTAD, 2018).

A diversificação dos IED em diferentes atividades revela também o potencial de diversificação econômica no continente. Para além das capacidades ociosas possíveis de serem solucionadas, a África conta também com o fator demográfico: com aproximadamente 1 bilhão de habitantes e taxas de fertilidade que são as mais altas do mundo, os países possuem ainda uma reserva significativa de força de trabalho e mercado consumidor para a economia internacional.

\section{AS MAIORES ENTRADAS E O MAIOR ESTOQUE DE IED NA ÁFRICA}

A cartografia dos IED se altera de ano para ano e reflete as possibilidades de investimentos que são construídas entre os governos nacionais e os governos e empresas estrangeiros. Em 2017, essas condições atraíram investimentos principalmente para Egito, Etiópia e Nigéria, apesar da África do Sul se manter como maior estoque de IED no mesmo ano, em função do acúmulo de projetos em desenvolvimento há mais tempo.

No Egito, mereceu destaque o aumento significativo de IED - especialmente chinês - na indústria de bens de consumo. No ano de 2017, o PIB alcançou os 235,5 bilhões de dólares, distribuídos pela agricultura $(11,7 \%)$, indústria $(34,4 \%)$ e serviços (54\%). A inserção egípcia na Divisão Internacional do Trabalho tem ocorrido nos últimos anos principalmente através da exportação de petróleo bruto (e seus derivados), mas também de frutas e algodão (vendidos principalmente para Emirados Árabes, Estados Unidos e Reino Unido). Já as importações estão centradas em maquinários, alimentos processados e produtos químicos (oriundos principalmente da China, dos Emirados Árabes, Estados Unidos e Rússia). Com saídas para o Mar Mediterrâneo e Vermelho, o país está em um ponto estratégico para a circulação de mercadorias entre Ásia, África e Europa, dado refletido na importância do Canal de Suez (inaugurado no final do século XIX) para a região (UNCTAD, 2018; CIA, 2019; OEC-MIT, 2019). 
Possuindo a maior parte de seu território em áreas desérticas, o Egito dispõe de um adensamento de suas forças produtivas ao longo do Rio Nilo, onde estão localizadas suas áreas rurais e urbanas. Trata-se do terceiro país mais populoso do continente, com 99,4 milhões de habitantes (47,8\% vivendo nas cidades). O IDH de 0,690 revela condições médias de vida no contexto planetário: com $80 \%$ da população alfabetizada, expectativa de vida entorno de 73 anos e um PIB per capta de 12 mil dólares, um dos grandes desafios encontrados no Egito são as elevadas taxas de desemprego (29,6\%), que reduzem o preço da força de trabalho e dão vazão à ocupações informais, especialmente no setor de serviços (CIA, 2019).

A Etiópia, por sua vez, absorveu IED - especialmente chineses e turcos destinados às indústrias de bens de consumo duráveis e não duráveis. Em 2017, as empresas estrangeiras que passaram a produzir no país foram: Calvin Klein, Tommy Hilfiger, Levi's, Zara, Under Armour, Giorgio Armani e Hugo Boss (têxtil e calçados), de modo que boa parte das fábricas dessas empresas está localizada no complexo etíope Hawassa Industrial Park, construído pelos chineses em 2016. Apesar de ter sido o segundo país que mais recebeu Investimentos Estrangeiros Diretos na África, a economia etíope possui um rendimento marcadamente inferior aos países mais ricos do continente: seu PIB alcançou os 80,5 bilhões de dólares em 2017, distribuídos pela agricultura $(34,8 \%)$, indústria $(21,6 \%)$ e serviços $(43,6 \%)$.

Dentre as principais mercadorias exportadas estão o café, óleos vegetais, vegetais comestíveis e ouro (vendidos principalmente para o Sudão, Suíça, China, Somália e Holanda). As importações, por sua vez, correspondem à maquinários, aviões, minerais diversos, produtos derivados do petróleo, eletrônicos, motores etc. (oriundos principalmente da China, Arábia Saudita e Índia). Sem possuir saídas para o mar, o território etíope esta articulado por rodovias e ferrovias aos Portos do Djibuti, Somália e Eritreia, fato que, em certa medida, aumenta a sua vulnerabilidade comercial (UNCTAD, 2018; CIA, 2019; OEC-MIT, 2019).

No espaço geográfico predominam paisagens de estepes, savanas e vegetações rasteiras de altitude em algumas áreas planálticas. As maiores densidades demográficas são observadas na porção central do território etíope, especialmente nos distritos próximos à capital Adis-Abeba. Segundo país mais 
populoso da África - com 108,3 milhões de habitantes (sendo que 20,8\% vivem nas cidades) - a Etiópia possui um IDH baixo $(0,442)$, que pode ser decupado pelos baixos índices de alfabetização (49,1\%), expectativa de vida (63 anos) e PIB per capta $(2,2$ mil dólares por ano). Assim, o Estado dessa formação socioespacial possui numerosos desafios no sentido de desenvolver as suas forças produtivas e o bemestar de sua população, que ainda figura no mapa da fome (CIA, 2019).

Na Nigéria, terceiro país que mais recebeu IED em 2017, a absorção de investimentos estadunidenses esteve associada ao mercado tecnológico (com a entrada regional do Uber e Facebook). Enquanto isso, os investimentos chineses se direcionaram à industrial têxtil, automobilística e aeronáutica. $O$ país é a maior economia africana, possuindo um PIB de 375,8 bilhões de dólares distribuídos pela agricultura $(21,2 \%)$, indústria $(22,5 \%)$ e serviços $(56,4 \%)$. Seus principais produtos de exportação são petróleo bruto (e derivados), além de cacau e borracha (vendidos para países como Índia, Estados Unidos, Espanha, China e França). As importações são sobretudo de maquinários, produtos químicos e de transporte, além de manufaturados em geral (oriundos da China, Bélgica, Estados Unidos, Coreia do Sul e Reino Unido). O comércio internacional é facilitado pela saída do país ao Golfo da Guiné, no Oceano Atlântico (UNCTAD, 2018; CIA, 2019; OEC-MIT, 2019).

Localizada sobre espaços onde se desenvolveram florestas tropicais e savanas, a formação socioespacial nigeriana é a mais populosa da África, possuindo 203 milhões de habitantes, dos quais 50,3\% vivem em cidades. Com o IDH de 0,514, considerado baixo, a Nigéria enfrenta desafios em função das baixas taxas de alfabetização (59,6\%), expectativa de vida (59,3 anos) e PIB per capta (5,9 mil dólares). O foco da agenda econômica dos governos nigerianos entorno da exploração e exportação do petróleo garantiram o enriquecimento do país, apesar de terem alienado a estrutura produtiva do mesmo (WATTS, 2013; CIA, 2019).

Mesmo não estando entre os países que receberam os maiores fluxos de IED em 2017, a África do Sul é a formação socioespacial que possui na atualidade o maior estoque desse tipo de investimento (150 bilhões de dólares, $18 \%$ do total no continente). Em seguida, figuram Egito (110 bilhões, 13\%), Nigéria (98 bilhões, 11\%), 
Marrocos (63 bilhões, 7\%), Moçambique (38 bilhões, 5\%) e Gana (33 bilhões, 4\%) (UNCTAD, 2018).

Os IED no país estão centrados nas atividades de indústria e de serviços. De acordo com a UNCTAD:

\begin{abstract}
O projeto de destaque foi o investimento da DuPont (Estados Unidos) em um centro regional de pesquisa de culturas secas. O IED automotivo também permaneceu significativo. A General Motors vendeu sua fábrica na África do Sul para a Isuzu do Japão, e a Beijing Automotive Group Co. anunciou um investimento de US \$88 milhões em uma fábrica de veículos em uma joinventure com a Industrial Development Corporation da África do Sul. Os investidores europeus, liderados pela Alemanha e pelo Reino Unido, permaneceram muito ativos na África do Sul, por meio de iniciativas como a reformulação de fábricas da BMW. O IED automotivo na África do Sul está desenvolvendo cada vez mais cadeias de valor regionais: o Lesoto agora produz assentos de automóveis e conjuntos de fiação de ignição de Botswana para fabricantes de automóveis na África do Sul (UNCTAD, 2018: 42, tradução do autor).
\end{abstract}

A África do Sul possui a economia mais diversificada do continente, bem como a infraestrutura mais eficiente. O PIB do país alcançou os 349,4 bilhões de dólares em 2017 , distribuídos pela agricultura $(2,8 \%)$, indústria $(29,7 \%)$ e serviços $(67,5 \%)$. Os principais produtos de exportação são ouro, diamante, além de maquinários e equipamentos (vendidos para a China, Estados Unidos, Alemanha, Japão, Índia, Botsuana e Namíbia). As importações são principalmente de maquinários e equipamentos, produtos químicos, derivados do petróleo, instrumentos científicos e alimentos processados (oriundos da China, Alemanha, Estados Unidos, Arábia Saudita e Índia) (UNCTAD, 2018; CIA, 2019; OEC-MIT, 2019).

Localizada em uma posição estratégica - entre os Oceanos Atlântico e Índico - a África do Sul corresponde a uma importante rota de circulação entre a Ásia e a América do Sul. O país possui formações de estepes, savanas, desertos e vegetação mediterrânica (no extremo sul), de modo que a população - de 55,3 milhões de habitantes, dos quais $66,4 \%$ vivem em cidades - concentra-se principalmente na porção oriental do país. A formação socioespacial sul africana possui um IDH médio $(0,666)$ e ainda enfrenta muitos desafios no tocante a saúde (a expectativa de vida media da população é de 64,1 anos), uma vez que a taxa de alfabetização $(94,4 \%)$ e o PIB per capta (13,6 mil dólares) estão entre os melhores do continente (CIA, 2019). 
A importância em se compreender a geografia dos Investimentos Estrangeiros Diretos na África se deve ao fato de que o seu fluxo se revela marcadamente seletivo, haja visto a diversidade de arranjos das forças produtivas forjadas em cada formação socioespacial ao longo do processo histórico. Desses arranjos surgem também as capacidades ociosas, que podem se tornar objeto de investimento na medida que os Estados nacionais se articulam aos capitais estrangeiros.

\section{CONSIDERAÇÕES FINAIS}

O crescimento econômico africano está na ordem dia. Certamente, as dinâmicas recentes do desenvolvimento econômico chinês e sua expansão no Sul Global - em forma de acordos comerciais bilaterais, empréstimos e financiamentos de múltiplos projetos - foram catalisadores do aprimoramento das forças produtivas de muitas formações socioespaciais do continente, especialmente daquelas que poderiam servir melhor aos interesses do gigante asiático.

Não se pode, contudo, condicionar o crescimento econômico africano exclusivamente ao dinamismo econômico chinês. O que se observa na atualidade nos países africanos é o esforço político dos chefes de Estados (e seus quadros técnicos) em resolver os limites impostos pelas capacidades ociosas de seus respectivos territórios, criando, para tanto, condições de atração dos IED. Esses investimentos permitem não apenas o desenvolvimento das forças produtivas, mas também a absorção de tecnologia, a criação de empregos (formais) e o desenvolvimento do capital nacional (público ou privado).

São 54 países africanos responsáveis por uma multiplicidade de estratégias de desenvolvimento que, nos próximos anos, se assemelharão ou se diversificarão em função dos arranjos das forças produtivas e das políticas implementadas pelos seus governos. A atenção ao continente não recai mais apenas sobre suas extensas e diversificadas reservas de recursos naturais. Para além disso, a China não é a única potência que compreendeu o papel que os africanos terão no mundo nas próximas décadas. A presença estadunidense segue vigorosa, assim como a do Reino Unido, 
da França, da Índia etc. Quanto mais cedo forem feitos os investimentos estrangeiros diretos nos países do continente, mais atentos ao futuro estarão os que investiram.

\section{REFERÊNCIAS}

ADEDEJI, Adebayo. "Estratégias comparadas da descolonização econômica”. In: MAZRUI, Ali. et al. (orgs.). História Geral da África VIII: África desde 1935. São Paulo: Cortez; Brasília: UNESCO, 2010.

AMIN, Samir. “Ideology and development in Sub-Saharan Africa”. In: ANYANG' NYONG'O, Peter. 30 years of independence in Africa: the lost decades? Nairobi: African Association of Political Science (AAPS), 1992.

ASIEDU, Elizabeth. "Foreign Direct Investment, Growth, and Poverty Reduction in Sub-Saharan Africa". In: ARYEETEY, Ernest et al. (orgs.). The Oxford Companion to the Economics of Africa. Nova lorque: Oxford, 2012, ps. 329-336.

BRAUTIGAM, Deborah. "Flying Geese" or "Hidden Gradon"? Chinese business and African Industrial Development. In: ALDEN, Chris et al. (orgs.). China returns to Africa: a rising power and a continent embrace. Londres: Hurst \& Company, 2009.

CHOLLEY, Andre. "Observações sobre alguns pontos de vista geográficos”. Boletim de Geografia, IBGE: Rio de Janeiro, 1964. No. 179.

CIA - CENTRAL INTELLIGENCE AGENCY. World Fact Book. Disponível em:

<https://www.cia.gov/library/publications/the-world-factbook/geos/gh.html> Acesso em: 10 mai. 2019.

DAVIDSON, Basil. A history of West Africa: 1000-1800. Londres: Longman, 1985.

FMI - FUNDO MONETARIO INTERNACIONAL. 2019. Disponível em:

<https://www.imf.org/external/index.htm MI, 2019>. Acesso em 10 Mai. 2019.

FOSU, Augustin; ARYEETEY Ernest. Ghana's post-independence economic growth: 1960-2000. In: ARYEETEY, Ernest; KANBUR, Ravi (orgs.). The economy of Ghana: analytical perspectives on stability, growth \& poverty. Oxford: James Currey, 2008.

GRANT, Richard. Africa: geographies of change. Nova lorque: Oxford University Press, 2015.

KILLICK, Tony. Development economic in action: a study of economic policies in Ghana. Londres; Nova lorque: Routledge, 2010.

MAMIGONIAN, Armen. Introdução ao pensamento de Ignacio Rangel. Geosul. Florianópolis, 1987. No. 3. Pp. 63-71.

MAMIGONIAN, Armen. A geografia e a formação social como teoria e como método. In: AUTORES. Seminário Internacional: O Mundo do cidadão, Um Cidadão do Mundo, USP, set. 1996.

MKANDAWIRE, Thandika. "30 years of African Independence: the economic experience". In: ANYANG' NYONG'O, Peter. 30 years of independence in Africa: the lost decades? Nairobi: African Association of Political Science (AAPS), 1992.

ORGANIZAÇÃO PARA COOPERAÇÃO E DESENVOLVIMENTO ECONÔMICO. 2019. Disponível em: <http://www.oecd.org> Acesso em: 10 mai. 2019.

OEC-MIT - OBSERVATORY OF ECONOMIC COMPLEXITY. 2019. Disponível em: $<$ http://atlas.media.mit.edu/en/> Acesso em: 10 mai. 2019.

OPEP - ORGANIZAÇÃO DOS PAÍSES EXPORTADORES DE PETRÓLEO. 2019. Disponível em: <https://www.opec.org/opec web/en/> Acesso em: 10 mai. 2019.

PAGE, John. "Industry for Africa. Why? How?" In: ARYEETEY, Ernest et al. (orgs.). The Oxford 
Companion to the Economics of Africa. Nova lorque: Oxford, 2012, ps. 304-311.

RAMACHANDRAN, "Vijaya. Africa s private sector". In: ARYEETEY, Ernest et al. (orgs.). The Oxford Companion to the Economics of Africa. Nova lorque: Oxford, 2012, ps. 312-320.

RANGEL, Ignacio. Recursos ociosos e política econômica. Sao Paulo: Hucitec, 1986.

SANTOS, Kaue Lopes dos. Pontas em circuito: as inserções de Gana na divisão internacional do trabalho contemporânea. Tese (Doutorado em Geografia Humana) - Faculdade de Filosofia, Letras e Ciências Humanas, Universidade de São Paulo, São Paulo, 2017.

SANTOS, Milton. Sociedade e espaço: a formação social como teoria e como método. Boletim Paulista de Geografia. São Paulo, n. 54, AGB, 1977, p.35-59.

SMITH, Noah. Africa is the future and China knows it. 2018. Disponível em:

<https://www.bloomberg.com/opinion/articles/2018-09-21/africa-economy-west-should-try-to-matchchinese-investment> Acesso em: 10 mai. 2019.

TIME MAGAZINE, The agony of Africa. 1992. Disponível em:

<http://content.time.com/time/covers/0,16641,19920907,00.html> Acesso em: 10 mai. 2019.

TIME MAGAZINE, Africa rising. 2012. Disponível em:

<http://content.time.com/time/covers/europe/0,16641,20121203,00.html>. Acesso em: 10 mai. 2019.

UNCTAD - UNITED NATIONS CONFERENCE ON TRADE AND DEVELOPMENT. World investment Report: investment and new industrial policies. 2018. Disponível em: <https://unctad.org> Acesso em: 10 mai. 2019.

UNECA - UNITED NATIONS ECONOMIC COMMISSION FOR AFRICA. 2019. Disponível em: <https://www.uneca.org> Acesso em: 10 mai. 2019.

WATTS, Michael. Silent Violence: Food, famine, and peasantry in Northern Nigeria. Athens: University of Georgia Press, 2013.

\section{NOTAS DE AUTOR}

\section{CONTRIBUIÇÃO DE AUTORIA}

Kauê Lopes dos Santos - Concepção. Coleta de dados, Análise de dados, Elaboração do manuscrito, revisão e aprovação da versão final do trabalho

\section{FINANCIAMENTO}

Gostaria de agradecer ao financiamento concedido pela Fundação de Amparo à Pesquisa do Estado de São Paulo (FAPESP) em de minha pesquisa de pós-doutorado na Universidade de São Paulo (Processo: 2017/ 22067-0) e na London School of Economics and Political Sciences (Processo: 2019/11987-7).

\section{CONSENTIMENTO DE USO DE IMAGEM}

Não se aplica.

\section{APROVAÇÃO DE COMITÊ DE ÉTICA EM PESQUISA}

Não se aplica

\section{CONFLITO DE INTERESSES}

Não se aplica.

LICENÇA DE USO - uso exclusivo da revista

Este artigo está licenciado sob a Licença Creative Commons CC-BY. Com essa licença você pode compartilhar, adaptar, criar para qualquer fim, desde que atribua a autoria da obra.

HISTÓRICO - uso exclusivo da revista

Recebido em: 5-2-2019

Aprovado em: 3-10-2019 